\title{
Social Media as the Next Trend in Social Business Marketing Social Media as the Next Trend in Solar Business Marketing
}

\author{
Vardhini V, P. Raja, Kabirdoss Devi
}

\begin{abstract}
In today's era, everyone have online presence. Someone will have more presence, someone will have less presence. Someone will be on mail and Facebook only and someone will be on everything from mail to Facebook, Twitter, Instagram, Linkedin etc. For Business, they are the perfect target. One can reach as many as potential customers and leads through social media all over the world which they can never achieve through any other media. Social media can be interactive and informative. New generation is highly active in social media at the same time they are highly aware of the growing concerns like global warming. New generation knows the importance of change and they encourage any noble cause all over the world. Even though solar business are present for a very long time but now only it is gaining importance after growing concerns towards our Mother Nature. To reach maximum target customers, it is very important for the Solar business to take leverage of Social media. Posting an article, or blog or uploading a video is not enough, if you are not targeting the correct viwers and you are not converting your viwers into leads. In this article, we would understand that how solar business can get fullest from social media and how to increase your customer base. Social media may sound like informal way to serve the customers but it is a powerful relationship builder for the company. Social media is very important to inspire and build strong relationship with the potential customers.
\end{abstract}

Keywords - Solar business, Social Media, Potential customers, Global warming, Leverage.

\section{INTRODUCTION}

Today is an Internet era, where everyone is connected with everyone in the world. Social media is becoming largest means of communication around the world. It is gaining tremendous amount of popularity, you can share your thoughts, ideas, information and news etc at lightning speed with everyone. In the last decade, social media has grown tremendously; spread worldwide and captured million of users. so, first we have to understand what is Social Media? Social Media includes websites and applications that enable users to create and share content or to participate in social networking. The impact of social media is high and far reaching and its effects on each individual who are using. We have included social media so much in our lives that today it is very difficult for us to imagine our life without it and yes it is a curse that we carry. It has become an essential evil.

Revised Manuscript Received on September 10, 2019.

Vardhini V, Research Scholar, Bharathair University, Coimbatore, Tamil Nadu, India.

(Email: vardhiniarunprasad@gmail.com)

Dr. P. Raja, Director, SIVET College, Chennai, Tamil Nadu, India.

(Email: rajampr@gmail.com)

Dr, Kabirdoss Devi, Asst. Professor (SG) , Saveetha Engineering

(Email: devikabirdoss@gmail.com) College, Chennai, Tamil Nadu, India.

There are lot of positive effects of social media. It is a great platform to communicate and share, connect and educate.

Social media has been really helpful for businesses. Companies are enabling to connect with more target customers, serve more customers. Today's business has become borderless because of social media. A person from India can buy a product from USA within minutes with the help of social media. Everyone uses social media but youths are highly active in social media. One of the boons of social media is that we can spread the information worldwide very fast. Social media can be effectively used to create awareness regarding social concerns.

This is a righteous era, where everyone wants to do good for the nature, for the society. Today's generation is well aware of the growing social concerns like global warming and understands the importance of change. Everyone actively support the noble causes, even if they are not doing anything to support the cause in person, they do one thing for sure and that is supporting it online i.e social media.

Today, a very high alert problem which concerns everyone is global warming and issues which are causing global warming. In last few decades human being was so focused in their own development and inventing new things that they forgot that their developments are causing problem to our mother nature which will backstab the human race. We started using the non-renewable energies at an alarming rate and now everyone is concern regarding their extinction. Everyone is searching for and opting alternative energies like solar, wind, hydro energy and bio fuel, to reduce the pollution which is causing global warming and also to preserve the non renewable energies.

Among all the renewable energies, solar energy is the most easily attainable source for a common man. Given right circumstances, anyone can install solar grid in the open space or on the terrace of their house and start using solar power in the form of electricity or hot water etc.

\section{SOCIAL MEDIA IN ITS RISE}

The lovechild of World Wide Web is Social media, it comes in many forms like photo sharing, information sharing, blogging, chat apps, business networks and forms etc. Today Social media is everywhere, everyone is using it. Social media helps to connect with friends and family, make new friends, and seek advice from the professionals in their field all over the world. Even kids are watching you tube

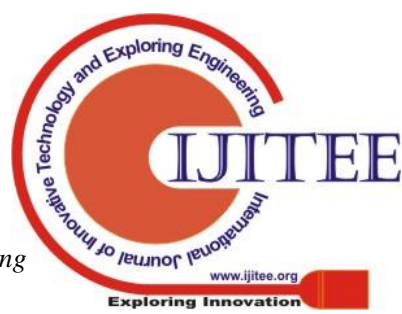


Kids, Whats app is the new way of communication and of sharing information, Facebook, Twitter, and Instagram has become a new platform to promote your business.

Social media has truly made the whole world as one family. We can connect with anyone in the world and we can buy product from any corner of the world. There are no boundaries today. It's a borderless, paperless and virtual world. Different countries have different penetration level of social media. To target the right audience, one must understand the reach of different social media in different countries and among different demographics. Some social media are more popular than the others.

According to Global Digital Report 2019, Total number of social media users worldwide in 2019 is 3.48 billion. On an average every person have 7.6 social media accounts. Social media users increased by 202 million from April 2018 and April 2019 that means in every 6.4 seconds a new person starts using social media. Global average of social media penetration worldwide is $45 \%$ whereas the social media penetration in UAE is $99 \%$, way above the global average. In the third world countries the penetration is less than average. In India, social media penetration in 2019 is only $23 \%$, in Ghana it is $19 \%$, Kenya it is $16 \%$ and Nigeria it is only $12 \%$. In India, the main users of social media are urban population. Social media has not reached to the rural India.

Social media is becoming more important for the business to grow. In $2018-19,91 \%$ of retailers use 2 or more social media channels to promote their products. $81 \%$ of small and medium businesses use some kind of social platforms. With the correct platform, audience and content one can either rise the brand to the stars or burn it to ashes. Social media has become a very important medium and plays a crucial role in creating the image of the brand. Customers have become smarter. Before buying any product or services, customers seek for the review and feedback about the brand. Social media is a good source of quality information. It is a great educational tool too. Social media has changed our lives, connected us with everyone, made our lives easy but it also have its shortcomings. Many people are getting addicted to it, they are losing the touch of real world. People are getting information overload. It is very difficult to differentiate between authentic information and fake information. Due to which lot time, money and energy is getting wasted.

Keeping the negative sides apart, social media has contributed substantially in the growth of our society. Social media can be used positively to create awareness for pressing causes that concerns society. Government can use social media effectively to spread awareness and fight crime.

\section{SOLAR POWER AS A SOURCE OF ALTERNATE ENERGY}

\section{Why renewable energy or alternate energy?}

Renewable energy is a clean energy and non-polluting. It is sustainable because it is generated from the sources that are inexhaustible like wind, solar, biomass and hydro that are given to us by our mother nature. In the process of producing electricity through renewable sources, it do not

emit any greenhouse gases or toxic waste whereas there are many negative consequences of burning fossil fuels, it emits large amount of carbon di oxide in the atmosphere which will further deteriorate the situation of global temperature changes. But on the other hand, renewable energy sources are reliable for a long term. Renewable energy is cost effective and efficient.

Due to greenhouse effect and climatic changes, many nations are encouraging the use of renewable energy. Greenhouse effect and climatic changes are not the only issues we are facing due to burning of fossil fuels. Gases emitted during burning of fossil fuels combined with the chemicals in the atmosphere produce harmful side effects some of them are acid rain and smog which damaging the environment, human body and the infrastructures. It is wreaking havoc on the economies. Aside of these spinoffs, fossil fuels are non renewable resources. It took millions of years for the nature to decompose the remains and convert it into fossil fuels. But with the rate we are digging fossil fuels from the earth, the day is not far off when the fossil fuel will get extinct. Our demand will soon exceed the supply of fossil fuel by the nature and it will take another millions of years for our nature to produce fossil fuels

One of the renewable energy is solar energy. We receive solar energy from the sun which is in this universe before there was life on earth and will be there even after billion of years. So, Solar energy is sustainable, clean and pollution free. In India, with 300 clear and sunny days, we clearly have the geographical advantage for using the solar power. In India, solar power is a fast growing industry. Solar power is been recognized by the policy makers as preferred technical solution for for the climate change and a stable energy source. Government's growing concern is regarding country's energy security. After the two oil shocks in 1970s which resulted in sudden increase in the price, uncertainties with the supply and negative effect on the balance of payment; energy self-sufficiency was seemed to be the solution to the problem in hand. To attain the goal of energy self-sufficiency, Government has established department as Ministry of New and Renewable Energy (MNRE) whose sole motive is to develop the alternate source of energy in India. Apart from this lots of commissions, missions, plans, policies have been launched in order to attain the goal of energy self sufficiency. The Jawaharlal Nehru National Solar Mission was launched by then Prime Minister, Dr. Manmohan Singh.

\section{SOCIAL MEDIA AND LEVERAGE TO SOLAR COMPANIES \& RESULTS}

Social media can be very beneficial to the solar companies. Social media have largest reach around the world. One can reach vast number of potential customers through social media. Solar companies must take the advantage of social media.

With the help of social media, solar companies can educate the public, promote their product and inspire the 
public to consider and try solar as an alternate energy. Solar companies can increase the awareness regarding solar by providing more information through social media. Solar companies can explain the benefits and affordability of soalr energy as an alternate energy. Social media not only create awareness but also create relationship between solar companies and consumers. This is a young industry with lot of scope to exceland acquire large market share. To gain the market share, companies must understand the needs of the customers and demonstrate that they understands the customer's position.

Social media represents tremendous opportunity to reach the target customers. Most active customers in different platforms of social media like Facebook, Twitter, Instagram, Linkedin are youth, educated, and economically well off. Those are the target customers who understands the importance of alternate energy. Active customers of social media cherish progressive ideas like environmentally conscious. People like to visit social media in search of information and for doing the research on the intended topic. Social energy is still a progressive idea and customers have lots of doubts and needs lots of explaination. Social media provides a perfect platform for the solar companies to explain their products and its importance and become a thought leader.

To take full advantage of social media without wasting it as a resource, solar companies must have strong strategies.

\section{E mail marketing is out of fashion:}

Company send mails to their list of contact that means, company ius approaching the already known contacts, they are not new and prospective customers. Social media is hotbed for leads. Company should post videos, blogs, and articles frequently.

\section{Gain the trust:}

Company should project themselves as a resource. Company should be loyal to the customers. Create an interactive posts whether in the form of blogs, videos or others, you must start the conversation and encourage the viewers to participate. You must showcase yourself as a service which supports the concerns like global warming, extinction of fossil fuels, environmental imbalance etc. Your main aim is to educate the viewers and while educating you build the trust with them. After gaining the trust you can pitch in your sales. But you must understand that your tone should be buyer centric rather than product centric.

\section{Create the connection:}

To increase the sales, create an emotional connection with your target custmers. Customers are more likely to buy the products of the companies with which they feel comfortable or connected. You should convince the target customers that they are contributing in the nobel cause.

You should make your target customers feel important. You must respond your viwers. Post credible articles and videos and be responsive to the messages. Become trusted expert in your niche industry. The viwers should feel that you look forward to answer their quries and you give value to their feedbacks about your products and services.

\section{All roads lead to home:}

Company must increase the traffic to their website. For doing so they must understand the market, target customers and their need. Competitor's analysis is very important in understanding regarding what is happening in the solar industry.

There are multiple ways to increase the traffic to your website. Post regularly on social media platforms like Facebook, Twitter, and Instagram etc. but understand that you should not post the whole content. The whole content should be available only on your website. The part of the content on the social media platform should be attractive enough to pull the viewers to your website to see the whole content.

The main aim of your website should be to convert the email addresses into leads. For that, your social media platforms pages should be attractive, should be updated and there should be a link between social media platforms and your websites. Your website should also be updated and attractive. If there is no link between social media platforms and your websites then you are losing important leads.

\section{Optimize your search engine ranking}

Company must make sure that they are on the top of their competitors in the search result. It is known as Search engine Optimization (SEO). To optimize the result of a search engine, you should often post relevant contents; build your website with clean and accessible code. Create social signals, search engine ranks the websites on the basis of number of times the content is shared, so you must create a sharing button in your website.

Another way of increasing your presence online is Paid Search Engine marketing which offers Pay Per Click (PPC). Your advertisement pops up in the key positions whenever people search for relevant keywords and you have to pay only when someone has clicked your advertisement. In this you must understand that you must select the correct keywords otherwise you will be attracting the wrong crowd to your website who is not interested in your products. You will not be able to convert the traffic into the leads. The same thing will happen if your website is not designed properly.

\section{Matrics matters}

Figures are important. Company must know that how many people are viewing their contents on different social media platforms, among them how many viewers are visiting their websites after viewing the contents and how many of them are potential leads. There are tools available with the help of which it is possible to track which customers are interacting with your business on what platforms and in what ways.

People perceive solar products as complex and expensive and so they are resistant when it comes to investing in solar products. To overcome the barrier of this perception, a user friendly website plays a very important role in the success of your company. 


\section{CONCLUSION}

Social media plays a crucial role in everyone's life in today's world. Everyone is present in social media in some form. Social media is a great platform to reach to your target audience. It is also a perfect place to bring social causes and concerns to everyone's attention. Today's major concern which the whole world is facing is depletion of fossil fuels, increasing pollution and greenhouse effects. Solution of all these problems is to encourage using renewable resources like solar energy. We have abundant amount of soalr energy which can never be exhausted. Solar products industry is in rise. There are some strategies that can help these solar companies to penetrate into the society more successfully.

\section{REFERENCE}

1. Aimee, T. (2016). 'Make the most of social media and digital marketing for your solar business'. [Online] www.solarpowerworldonline.com. Available at: https://www.solarpowerworldonline.com/2016/12/makesocial-media-digital-marketing-solar-business/ [Accessed 31/07/2019]

2. Chaffey, D. (2019) 'Global Social Media Research Summary 2019' [Online] www.smartinsights.com. Available at: https://www.smartinsights.com/socialmedia-marketing/social-media-strategy/new-globalsocial-media-research/ [Accessed at 01/08/2019]

3. Colm, H. (2016). 'Why solar companies need social media'. [Blog]. www.hannondigital.com. Available at: https://www.hannondigital.com/blog/why-solarcompany-need-social-media/ [Accessed 01/08/2019]

4. RGR Marketing blog. (2018). '6-reasons-your-solarcompany-should-be-using-social-media.' [Blog] www.rgrmarketing.com. Available at: https://www.rgrmarketing.com/blog/6-reasons-yoursolar-company-should-be-using-social-media/ [Accessed 31/07/2019]

5. Smith, K. (2019). '126 Amazing social media statistics and facts'. [Online] www.brandwatch.com. Available at: https://www.brandwatch.com/blog/amazing-socialmedia-statistics-and-facts/ [Accessed at 01/08/2019]

6. Sunrun.com (2016). Sunrun's official website. [Online] Available at: https://www.sunrun.com/go-solarcenter/solar-articles/solar-as-an-alternative-energy-source [Accessed at 02/08/2019]

7. wikipedia.org (2018). 'Solar Power in India'. [Online] Available https://en.wikipedia.org/wiki/Solar power in India [Accessed at 02/08/2019] 